\title{
Dietary Intake and Bone Mineral Density Status Among Adolescents of Kurukshetra
}

\author{
Gunjan Soni $^{1, ~ *, ~ G u r s h a r a n ~ K a u r ~ K o c h a r ~}{ }^{2}$, Gurpreet Arora ${ }^{1}$ \\ ${ }^{1}$ Department of Home Science, Kurukshetra University, Kurukshetra, India \\ ${ }^{2}$ Department of Food Science, Central University of Haryana, Monhindergarh, India
}

Email address:

vermgunjan@gmail.com (G. Soni), kocharcup@gmail.com (G. K. Kochar), Mail2gurpreetarora@gmail.com (G. Arora)

${ }^{*}$ Corresponding author

\section{To cite this article:}

Gunjan Soni, Gursharan Kaur Kochar, Gurpreet Arora. Dietary Intake and Bone Mineral Density Status Among Adolescents of Kurukshetra. Journal of Food and Nutrition Sciences. Vol. 5, No. 3, 2017, pp. 63-68. doi: 10.11648/j.jfns.20170503.11

Received: February 26, 2017; Accepted: March 22, 2017; Published: April 7, 2017

\begin{abstract}
Long term calcium deficiency during adolescence leads to poor bone mineral accrual in and early onset of osteoporosis. Information on calcium intake was obtained by 24 hour recall method for three days. BMD of the whole body was measured by using dual-energy X-ray absorptiometry (DEXA). Mean calcium intake among 56.09\% of the subjects (396 out of 706) was less than recommended calcium (ICMR, 2011) i.e., $800 \mathrm{mg}$ daily. There was significant difference ( $\mathrm{p} \leq 0.003$ ) among male and female subjects in amount of calcium intake. In addition, higher number of female subjects $(80.67 \%)$ were taking less than recommended calcium RDA than their male counter parts $(43.59 \%)$. In males, out of total 72 and 239 male adolescent subjects of group I and II, 24(33.33\%) and 48 (20.08\%) subjects were found low in BMD respectively. While in females, out of total 48 and 50 male adolescent subjects of group I and II, 20 (41.67\%) and 22 (44\%) subjects were found low in BMD respectively. Hence, the results revealed that low BMD was present among the adolescent students of Kurukshetra district.
\end{abstract}

Keywords: Adolescence, Bone Mineral Density, Calcium Intake, Osteopenia

\section{Introduction}

Adolescence is the transition phase from childhood to adulthood. It is the critical time of life for the development of peak bone mass and bone accretion. "Calcium accumulates in bones at an average of $150 \mathrm{mg} /$ day. Acquisition rate are highest in infancy and in puberty and lower during other childhood years. Linear growth stop at the end of puberty, but bone mass continues to increase for some time afterwards, reaching the peak during young adulthood" [3]. Increase of peak bone mass in young persons could reduce the incidence of osteoporotic fractures in the later years. Due to poor dietary intake and increase interest in junk and continental food among adolescents, availability of calcium, has become low especially for vegetarians. Low calcium intake causes its deficiency and leads to inadequate bone mass accrual in childhood and adolescence. Low intake of calcium during growth years result in weak and fragile bone or low bone mass, which is one of the major factors responsible for osteoporosis in later ages. Therefore, this study was undertaken to assess the dietary intake and bone mineral density of adolescent school going students of Kurukshetra district (Haryana).

\section{Method and Materials}

\subsection{Selection of Subjects}

A total of 706 adolescent students, 468 males and 238 females, aged 11-16 years were randomly selected from $8^{\text {th }}$, $9^{\text {th }}$ and $10^{\text {th }}$ standards of different government schools of District Kurukshetra. Separate groups of male and female were formed, both of which were sub classified on the basis of age into two groups - group I (11 to 13 years) and group II (14 to 16 years). Female group I comprised of 97 subjects while Female group II comprised of 141 subjects. Similarly, Male group I comprised of 116 subjects while Male group II comprised of 352 subjects. Calcium intake and anthropometric measurements were done on these 706 
subjects. BMD was applied on 409 subjects (those have low dietary calcium intake). Male group I had 72 and group II 239 subjects, whereas, female group-I and group II had 48 and 50 subject respectively.

\subsection{Anthropometric Measurements}

Weight and Height measurements were measured for all subjects. Height was measured in centimetres by Seca 217 stadiometer (for mobile height measurement) using the methods of Jelliffe [14]. Weight was measured in kilograms using methods of Jelliffe [14] and ICMR [11]. These anthropometric measurements were compared with ICMR which helped determine growth performance, prevalence and incidence of degree of malnutrition among the adolescent's (both males and females). BMI of these adolescents was also assessed following the classification given by James et. al., [13].

\subsection{Dietary Survey and Calcium Intake Estimation}

Dietary calcium intake of each subject was calculated from the consumed food by him, via referring the calcium value of food determined in laboratory by atomic absorption spectrophotometer. The dietary intake of all the subjects was evaluated by 24 hour recall method during three consecutive days for calculating the total calcium intake.

\subsection{Bone Mineral Density (BMD) Measurements}

The Bone mineral density of subjects was determined using p-DEXA (peripheral dual-energy x-ray absorptiometry) method and measured by Ultrasound Bone Densitometer CM-200. For this measurement, the X-rays were applied on the right leg's heel (calcaneus) bone. Bone Mineral Density, expressed in grams per centimetre square and $\mathrm{T}$ score, was recorded for each of the subjects.

\subsection{Statistical Analysis}

Mean and standard deviation were calculated for anthropometric variables (height, weight and BMI), for dietary calcium intake and for bone mineral density separately for both group I and group II of males and females. Anova was calculated among all the groups for calcium intake. The statistical significance was defined as $\mathrm{p}<0.01$.

\section{Result and Discussion}

\subsection{Anthropometric Measurements}

Table 1 shows anthropometric measurements of subjects

Table 1. Anthropometric measurements of male and female subjects of different age groups.

\begin{tabular}{lllll}
\hline Gender & Group & Subjects & Mean Weight (Kg) & Mean Height (cm) \\
\hline \multirow{2}{*}{ Male } & Group I & $116(24.79 \%)$ & $38.41 \pm 5.68$ & $150.40 \pm 12.41$ \\
& Group II & $352(75.21 \%)$ & $42.70 \pm 6.76$ & $159.60 \pm 11.01$ \\
\multirow{2}{*}{ Female } & Group I & $97(40.76 \%)$ & $37.00 \pm 4.86$ & $149.35 \pm 9.37$ \\
& Group II & $141(59.24 \%)$ & $39.19 \pm 5.51$ & $152.71 \pm 10.12$ \\
\hline
\end{tabular}

In males, the mean height in groups I (11-13 years) and II (14-16 years) was $150.40 \pm 12.41$ and $159.60 \pm 11.01 \mathrm{~cm}$ respectively, whereas, in females, mean height in groups I (11-13 years) and II (14-16 years) was 149.35 \pm 9.37 and $152.71 \pm 10.12 \mathrm{~cm}$ respectively. The Boys were slightly taller than girls in group-II (14-16 yrs.). Though there were minimal difference in mean height between males and females in Group I, marked differences were observed in mean height between males and females in Group II. Mean height difference between males and females diverged from minimal in group I (11-13 yrs) to males being $4.51 \%$ taller than females in group II.

In group I (11-13 yrs.), mean weight for males and females was $38.41 \pm 5.68 \mathrm{~kg}$ and $37.00 \pm 4.86 \mathrm{~kg}$ respectively, whereas, in group II, mean weight for males and females was $42.70 \pm 6.76 \mathrm{~kg}$ and $39.19 \pm 5.51 \mathrm{~kg}$ respectively. Like height, the akin pattern of differences in mean weight within both the groups of male and female was noticed, i.e. the males were $8.96 \%$ heavier from females in group II (14-16 yrs.) while the difference between mean male and female was minimal in group I.
In male subjects, groups I (24.79\%) and II (75.21\%), had mean BMI of $16.80 \pm 2.43$ and $17.11 \pm 2.76$, respectively. While for female subjects, group I (40.76\%) and II (59.24\%) had mean BMI of $16.72 \pm 2.82$ and $16.93 \pm 2.84$ respectively. BMI values were lower relative to ICMR standards [11] in the both groups of male as well as of females.

The mean height, weight and BMI in the both age groups of male and female was lower in the present study as compared to ICMR standards [11]. Chaturvedi et al [2] observed that the mean height of adolescent girls at 13,15 and 17 years was $148.1 \pm 7.3 \mathrm{~cm}, 152,2 \pm 7.3 \mathrm{~cm}$ and $154.1 \pm$ $5.9 \mathrm{~cm}$ respectively. Ayoola et al [1] also concluded that low relative height and underweight occur in a large proportion of children and adolescents in rural Nigeria, and further added that the lowest relative heights and weights occurred in midadolescence and among males.

\subsection{Dietary Calcium Intake Assessment}

Table 2 shows the eating pattern of subjects.

Table 2. Eating pattern of male and female subjects of different age groups.

\begin{tabular}{llll}
\hline \multirow{2}{*}{ Eating pattern } & Male & & Female \\
\cline { 2 - 4 } & Group-I & Group-II & Group-I \\
\cline { 2 - 4 } & Subjects N=116 & Subjects N=352 & Subjects N=97 \\
\hline Vegetarian & $72(62.07 \%)$ & $224(63.64 \%)$ & $63(64.94 \%)$ \\
\hline
\end{tabular}




\begin{tabular}{lllll}
\hline \multirow{2}{*}{ Eating pattern } & Male & & Female & Group-II \\
\cline { 2 - 5 } & Group-I & Group-II & Group-I & Subjects N=141 \\
\cline { 2 - 5 } & Subjects N=116 & Subjects N=352 & Subjects N=97 & $30(21.28 \%)$ \\
\hline Non-vegetarian & $28(24.14 \%)$ & $68(19.32 \%)$ & $16(16.49 \%)$ & $18(18.56 \%)$ \\
Eggetarian & $16(13.79 \%)$ & $60(17.05 \%)$ & $18(18.55 \%)$ & \\
\hline
\end{tabular}

Male Group I

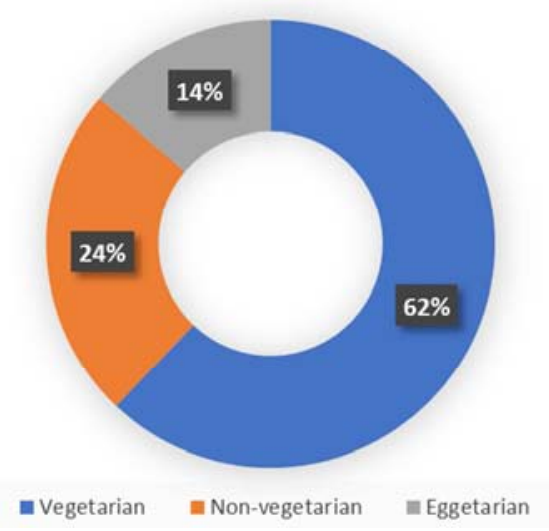

Male Group II

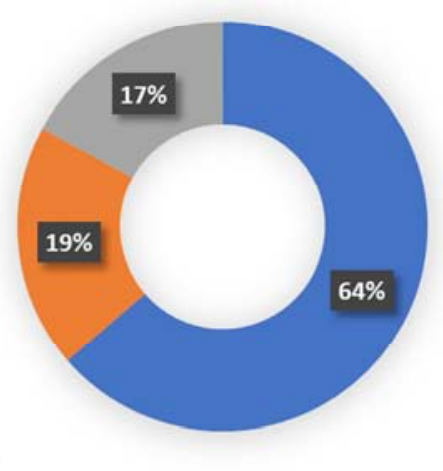

Figure 1. Eating pattern of male subjects of different age groups.

\section{Female Group I}

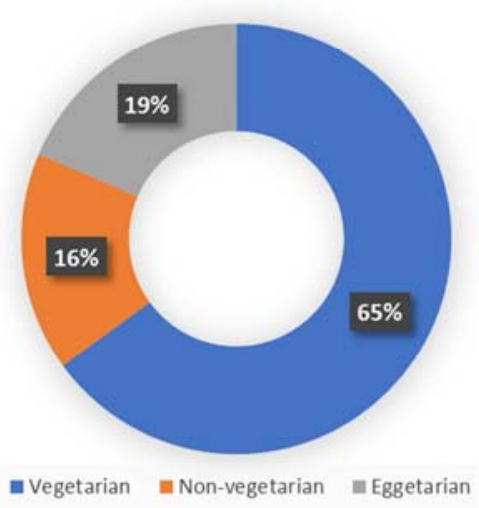

\section{Female Group II}

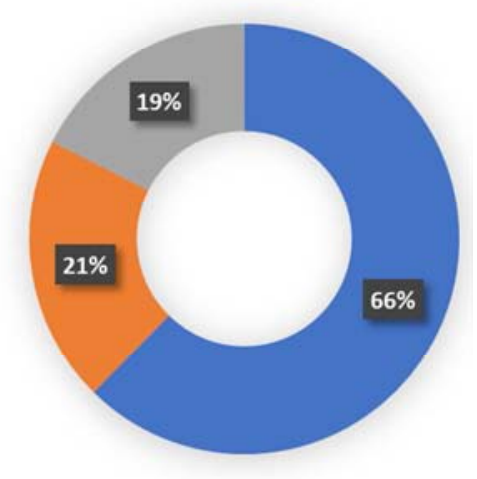

Figure 2. Eating pattern of female subjects of different age groups.

It was found that in male groups I and II majority of subjects $72(62.07 \%)$ and $224(63.64 \%)$ were vegetarian. The number of non-vegetarian in group I and II were 224 $(63.64 \%)$ and $68(19.32 \%)$ while the number of eggetarian in group I and II were $16(13.79 \%)$ and $60(17.05 \%)$. Female group I had $63(64.94 \%)$ vegetarian, 16 (16.49\%) nonvegetarian and 18 (18.55\%) eggetarian, whereas, in group II of females $93(65.96 \%)$ were vegetarian, $30(21.28 \%)$ were non-vegetarian and $18(18.56 \%)$ were eggetarian. Eating pattern are presented graphically in figure 1 and 2 for these groups.

Subject's distribution and mean calcium intake with standard deviation has been shown in Table 3.

Table 3. Dietary calcium intake in surveyed male and female adolescent subjects of different groups.

\begin{tabular}{|c|c|c|c|c|c|c|c|}
\hline \multicolumn{8}{|c|}{ Mean calcium intake (mg) } \\
\hline \multirow{2}{*}{ Gender } & \multirow{2}{*}{ Group } & \multicolumn{3}{|l|}{$<800 \mathrm{mg}$} & \multicolumn{3}{|l|}{$>800 \mathrm{mg}$} \\
\hline & & Subjects N=396 & Mean Intake & $\%$ Adequacy & Subjects N=310 & Mean Intake & \% Adequacy \\
\hline \multirow{3}{*}{ Female } & Group I & $81(83.50 \%)$ & $486.33 \pm 46.27$ & $60.79 \%$ & $16(16.49 \%)$ & $851.63 \pm 29.22$ & $106.45 \%$ \\
\hline & Group II & $111(78.72 \%)$ & $499.83 \pm 125.35$ & $62.48 \%$ & $30(21.28 \%)$ & $855.58 \pm 17.15$ & $106.95 \%$ \\
\hline & Total & $192(80.67 \%)$ & $496.46 \pm 111.15$ & $62.06 \%$ & $46(19.33 \%)$ & $854.26 \pm 22$ & $106.78 \%$ \\
\hline \multirow{3}{*}{ Male } & Group I & $68(58.62 \%)$ & $538.53 \pm 123.42$ & $67.32 \%$ & $48(41.38 \%)$ & $939.5 \pm 110.53$ & $117.44 \%$ \\
\hline & Group II & $136(38.64 \%)$ & $607.91 \pm 117.01$ & $75.99 \%$ & $216(61.36 \%)$ & $884.65 \pm 68.03$ & $110.58 \%$ \\
\hline & Total & $204(43.59 \%)$ & $589.32 \pm 122.67$ & $73.66 \%$ & $264(56.41 \%)$ & $893.31 \pm 78.91$ & $111.66 \%$ \\
\hline Grand Total & & $396(56.09 \%)$ & $556.91 \pm 126.76$ & $69.61 \%$ & $310(43.91 \%)$ & $878.2 \pm 66.07$ & $109.77 \%$ \\
\hline
\end{tabular}


Table 4. Anova table of calcium intake of male and female groups.

\begin{tabular}{lllllll}
\hline ANOVA & & & & & \\
\hline Source of Variation & $\boldsymbol{S S}$ & $\boldsymbol{d f}$ & $\boldsymbol{M S}$ & $\boldsymbol{F}$ & $\boldsymbol{P}$-value & $\boldsymbol{F}$ crit \\
\hline Between Groups & 376541 & 3 & 125513.7 & 4.622084 & 0.00387 & 2.655647 \\
Within Groups & 4806472 & 702 & 27155.21 & & \\
Total & 5183013 & 705 & & & \\
\hline
\end{tabular}

Male Group 1

Male Group 2
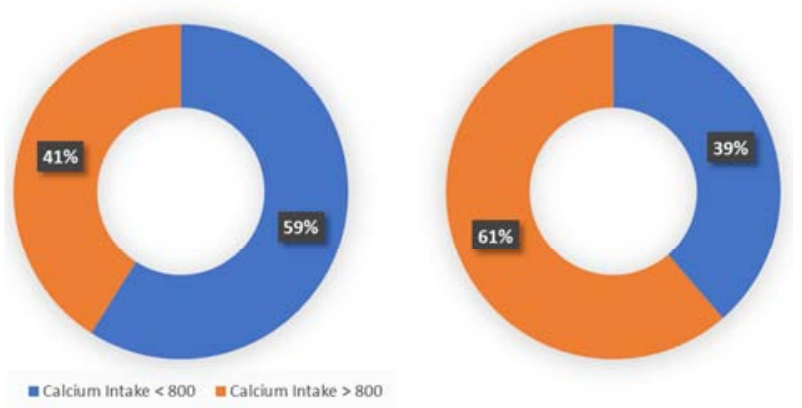

Figure 3. Prevalence of low dietary calcium intake in surveyed male subject groups.
Female Group 1

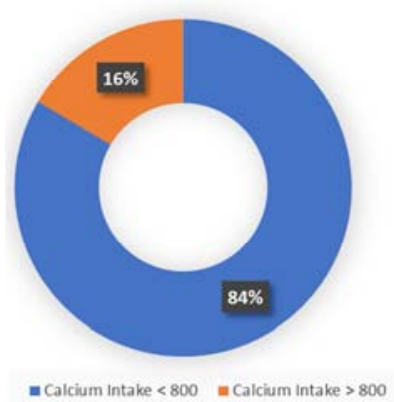

Female Group 2

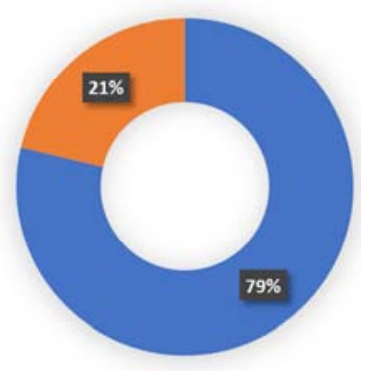

Figure 4. Prevalence of low dietary calcium intake in surveyed female subjects of different age groups.

Mean calcium intake among $56.09 \%$ of the subjects $(396$ out of 706) was less than recommended calcium (ICMR, 2011) i.e., $800 \mathrm{mg}$ daily. There was significant difference $(\mathrm{p} \leq 0.003)$ among male and female subjects of the groups in amount of calcium intake. In addition, higher number of female subjects $(80.67 \%)$ were taking less than recommended calcium RDA than their male counter parts $(43.59 \%)$. Mean dietary calcium intake was also higher among male groups (I and II) compared to female groups (I and II). Among the Females, 81 (83.50\%) subjects from group I and (78.72\%) from group II were taking below 800 mg (recommended by ICMR, 2011) of calcium per day. Mean calcium intake of these female groups I and II was $486.33 \pm 46.27$ and $499.83 \pm 125.35$ respectively. While for the male group, $68(58.62 \%)$ subjects with mean intake of $538.53 \pm 123.42$ calcium from group I and 136 (38.64\%) with intake of $607.91 \pm 117.01$ calcium from group II were taking less than recommendation per day. Among female groups, only $16(16.49 \%)$ subjects from group I and $30(21.28 \%)$ subjects from group II were approaching recommended RDA of calcium with mean intake of $851.63 \pm 29.22$ (group I) and $855.58 \pm 17.15$ (group II) respectively. Whereas, 48 (41.38\%) respondents from male group I and 216 (61.36\%) respondents from male group II were reaching recommended level of calcium. Mean calcium intake of male group I and II was $939.50 \pm 110.53$ and $884.65 \pm 68.03$ respectively.

Thus, the result discloses that low dietary calcium intake was common among the adolescent students of Kurukshetra district. Rajeshwari et al. [15] followed a group of children from 10 years of age until adulthood and demonstrated that calcium intake was reduced at this age, despite the increased energy expenditure. Further, they found that there was a considerable reduction in total calcium intake in childhood (54\% below the recommended level) to adulthood $(77 \%$ below the recommended level). In Brazil, Lerner et al. [15] evaluated the calcium intake of adolescents in public schools in Osasco, SP, and found that though the mean daily calcium intake did not differ significantly between boys and girls, but it was around $50 \%$ of recommended in both cases (mean calcium intake of $628.85 \pm 353.82 \mathrm{mg} /$ day among the boys and $565.68 \pm 295.43 \mathrm{mg} /$ day among the girls). Just $6.2 \%$ of the boys and $2.8 \%$ of the girls had adequate calcium intake, in common with studies carried out in other countries. In another study, Salamoun et al. [16] evaluated the calcium and vitamin D intake of children and adolescents living in Mediterranean countries and found that intake of both nutrients was below optimum levels (mean calcium intake was $816 \pm 776.8 \mathrm{mg} /$ day and mean vitamin $\mathrm{D}$ intake was $129 \pm 116.1 \mathrm{IU} /$ day). Just $12 \%$ had adequate daily calcium intake, and $16 \%$ had adequate vitamin $\mathrm{D}$.

Harinaraynan et al. [9] found that the daily dietary calcium intake of both rural and urban subjects was low when compared with that of the recommended dietary allowance (RDA) of both sexes issued by the Indian Council of Medical Research (ICMR, 20011) for the Indian population. Greer et. al., [6] found that Suboptimal intakes of calcium in children and adolescents may be related to the replacement of milk intake by soft drinks and fruit juices and/or fruit drinks. Softdrink consumption peaks in adolescence, at which time milk intake is at its lowest level. Only $10 \%$ of adolescent girls achieve the recommended adequate dietary intake of calcium of $1300 \mathrm{mg}$ per day. Calcium intake level among our sample is below the recommended international figure especially in girls. The majority of Egyptian children and teens do not consume enough dietary calcium on a daily basis, as reported in the national survey carried out by the National Nutrition Institute, Egypt (DNPCNCD 2008) [7].

\subsection{Radiographic Assessment}

Distribution of subjects according to BMD in surveyed 
male and female adolescent subjects of different groups has been shown in Table no 5.

Table 5. Bone Mineral Density of surveyed male and female adolescent subjects of different age groups.

\begin{tabular}{lllll}
\hline \multirow{2}{*}{ Condition } & Male & \multicolumn{3}{l}{ Female } \\
\cline { 2 - 5 } & Group I & Group II & Group I & Group II \\
\cline { 2 - 5 } & $\mathbf{N = 7 2}$ & $\mathbf{N}=\mathbf{2 3 9}$ & $\mathbf{N}=\mathbf{4 8}$ & $\mathbf{N}=\mathbf{5 0}$ \\
\hline Normal & $48(66.67 \%)$ & $191(79.92 \%)$ & $28(58.33 \%)$ & $28(56.00 \%)$ \\
Osteopenia & $24(33.33 \%)$ & $48(20.08 \%)$ & $20(41.67 \%)$ & $22(44.00 \%)$ \\
\hline
\end{tabular}

In males, out of total 72 and 239 male adolescent subjects of group I and II, 24(33.33\%) and $48(20.08 \%)$ subjects were found low in bone mineral density (osteopenia) respectively. While in females, out of total 48 and 50 male adolescent subjects of group I and II, $20(41.67 \%)$ and $22(44 \%)$ subjects were found low in bone mineral density (osteopenia) respectively. Hence, the results revealed that low bone mineral density (osteopenia) was present among the adolescent students of Kurukshetra district. Goulding et. al. [4] concluded that low bone density is more common throughout the skeleton in adolescent girls. Ibrahim S. A. [12] also found $45.2 \%$ suffered from osteopenia in boys and $26.5 \%$ suffered from osteopenia in girls aged between 10 to 18 years with normal height. Data from study done by Soyka et. al. [18] demonstrated that spinal osteopenia is common in adolescent girls with AN compared with a group of BA- and CA- matched healthy adolescents. In the patient group, $42 \%$ of AN subject had a lumbar spine BMD more than 1 standard deviation, and $16 \%$ had a lumbar spinal BMD more than 2 standard deviation.

Table no 6 shows mean bone mineral density with T-Score of male and female subjects in group I and group II.

Table 6. Mean bone mineral density with standard deviation of male and female subjects of different age groups.

\begin{tabular}{|c|c|c|c|c|c|c|c|c|c|c|c|c|}
\hline \multirow{3}{*}{$\begin{array}{l}\text { Bone } \\
\text { Mineral } \\
\text { Density }\end{array}$} & \multicolumn{6}{|l|}{ Male } & \multicolumn{6}{|l|}{ Female } \\
\hline & \multicolumn{3}{|l|}{ Group I } & \multicolumn{3}{|l|}{ Group II } & \multicolumn{3}{|l|}{ Group I } & \multicolumn{3}{|l|}{ Group II } \\
\hline & $\begin{array}{l}\text { Subjects } \\
\mathrm{N}=72\end{array}$ & $\begin{array}{l}\text { Mean } \\
\text { BMD } \\
\text { g/cm² }\end{array}$ & $\begin{array}{l}\text { Mean } \\
\text { T-Score }\end{array}$ & $\begin{array}{l}\text { Subjects } \\
\mathbf{N}=\mathbf{2 3 9}\end{array}$ & $\begin{array}{l}\text { Mean } \\
\text { BMD } \\
\text { g/cm } \\
\end{array}$ & $\begin{array}{l}\text { Mean T- } \\
\text { Score }\end{array}$ & $\begin{array}{l}\text { Subjects } \\
\mathrm{N}=48\end{array}$ & $\begin{array}{l}\text { Mean } \\
\text { BMD } \\
\text { g/cm2 }\end{array}$ & T-Score & $\begin{array}{l}\text { Subjects } \\
\mathbf{N}=\mathbf{5 0}\end{array}$ & $\begin{array}{l}\text { Mean } \\
\text { BMD } \\
\text { g/cm2 } \\
\end{array}$ & $\begin{array}{l}\text { T- } \\
\text { Score }\end{array}$ \\
\hline Normal & 33 & $\begin{array}{l}0.547 \pm \\
0.04\end{array}$ & $\begin{array}{l}-0.37 \pm \\
0.28\end{array}$ & 152 & $\begin{array}{l}0.528 \pm \\
0.04\end{array}$ & $\begin{array}{l}-0.50 \pm \\
0.25\end{array}$ & 19 & $\begin{array}{l}0.551 \pm \\
0.04\end{array}$ & $\begin{array}{l}-0.38 \pm \\
0.25\end{array}$ & 18 & $\begin{array}{l}0.526 \pm \\
0.03\end{array}$ & $\begin{array}{l}-0.50 \pm \\
0.28\end{array}$ \\
\hline Borderline & 15 & $\begin{array}{l}0.474 \pm \\
0.00\end{array}$ & $\begin{array}{l}-1.00 \pm \\
0.00\end{array}$ & 39 & $\begin{array}{l}0.472 \pm \\
0.01\end{array}$ & $\begin{array}{l}-1.00 \pm \\
0.00\end{array}$ & 9 & $\begin{array}{l}0.474 \pm \\
0.00\end{array}$ & $\begin{array}{l}-1.00 \pm \\
0.00\end{array}$ & 10 & $\begin{array}{l}0.478 \pm \\
0.00\end{array}$ & $\begin{array}{l}-1.00 \pm \\
0.00\end{array}$ \\
\hline Osteopenia & 24 & $\begin{array}{l}0.435 \pm \\
0.02\end{array}$ & $\begin{array}{l}-1.29 \pm \\
0.17\end{array}$ & 48 & $\begin{array}{l}0.440 \pm \\
0.02\end{array}$ & $\begin{array}{l}-1.25 \pm \\
0.20\end{array}$ & 20 & $\begin{array}{l}0.458 \pm \\
0.01\end{array}$ & $\begin{array}{l}-1.20 \pm \\
0.10\end{array}$ & 22 & $\begin{array}{l}0.399 \pm \\
0.04\end{array}$ & $\begin{array}{l}-1.60 \pm \\
0.40\end{array}$ \\
\hline
\end{tabular}

Male Group I

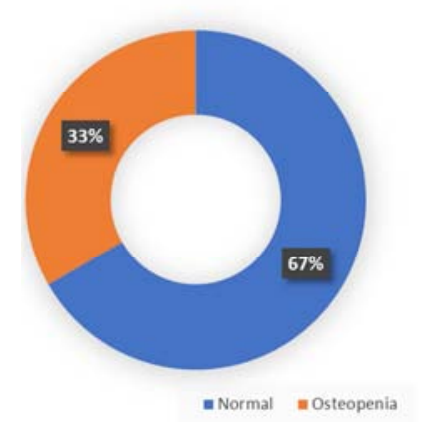

Figure 5. Prevalence of osteopenia in surveyed male subjects of different age group.
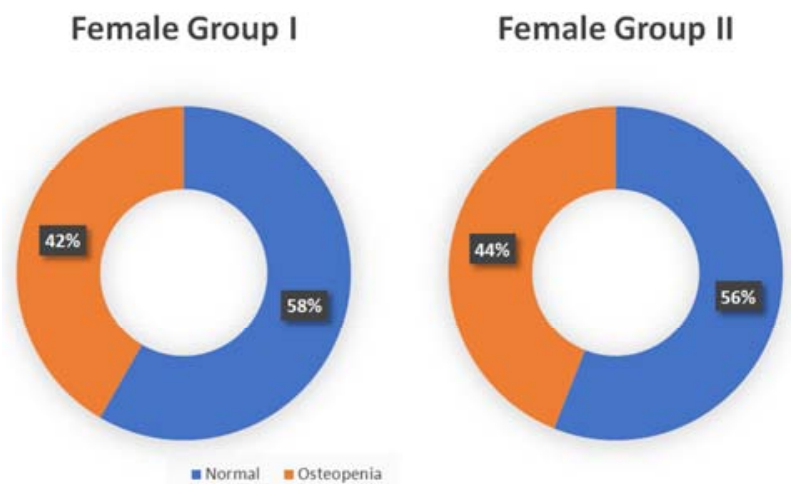

Figure 6. Prevalence of Osteopenia in surveyed female subjects of different age groups.
In males, mean bone mineral density (T-Score) of normal, borderline and osteopenic subjects of group I were $0.547 \pm 0.04 \quad(-0.37 \pm 0.28), \quad 0.474 \pm 0.00 \quad(-1.00 \pm 0.00) \quad$ and $0.435 \pm 0.02(-1.29 \pm 0.17)$ and of group II were $0.528 \pm 0.04$ ($0.50 \pm 0.25), \quad 0.472 \pm 0.01 \quad(-1.00 \pm 0.00), \quad 0.440 \pm 0.02 \quad$ ($1.25 \pm 0.20)$ respectively. Whereas, in females, mean bone mineral density (T-Score) of normal, borderline and osteopenic subjects of group I were $0.551 \pm 0(-0.38 \pm 0.25)$, $0.474 \pm 0.00(-1.00 \pm 0.00), 0.458 \pm 0.01 \quad(-1.20 \pm 0.10)$ and of group II were $0.526 \pm 0.03 \quad(-0.50 \pm 0.28), 0.478 \pm 0.00 \quad$ ($1.00 \pm 0.00), 0.399 \pm 0.04(-1.60 \pm 0.40)$ respectively. Goulding et. al. [4] reported lower bone mass at multiple sites in a group of 100 girls who were 3 to 15 years of age with distal forearm fractures compared with age-matched control girls. Goulding et al [5] reported in a different study lower bone mass at multiple sites compared with age-matched control boys. A previous national study by Hassan et al., [10] for the determination of bone mass density among Egyptian adolescents recorded osteopenia in $18 \%$ of male adolescents and $11 \%$ of Female adolescents and showed lower mean values of BMD T-scores than study by Ebtissam et. al., [8] ($1.38+1.06$ and $0.56+0.92$ for male and female adolescents respectively).

\section{Conclusion}

The low values of Mean calcium intake acquired from this study suggests that there is need for improvement in the recommended calcium intake among the adolescents in 


\section{Kurukshetra.}

Bone mineral study also indicated that adolescents of Kurukshetra are suffering from low Bone mineral density and this increases the likelihood of osteopenia among the adolescents at later stages of life which may result in further complications.

There is a need to ensure sufficient knowledge of nutrition and recommended calcium intake, calcium values of foods and awareness about osteopenia is spread among adolescents and the local populace so that they can ensure they are taking the right amount of calcium in their diets and identify early cases of Osteopenia and take corrective actions.

\section{References}

[1] Ayoola O., Ebersole K., Omotade O. O., Tayo B. O., Brieger W. R., Salami K., Dugas L. R., Cooper R. S.,2 and Luke A (2009). Relative Height and Weight among Children and Adolescents of Rural Southwestern Nigeria. Ann Hum Biol. 36[4]:388-399.

[2] Chaturvedi S., Kapil U., Gnanasekaran N., Sachdev H. P. S., Pandey R. M. and Bhanti T(1996). Nutrient intake amongst adolescent girls Belonging to poor socioeconomic group of rural area of Rajasthan. Indian Pediatrics. 33:197-201.

[3] Flynn A (2003) The role of dietary calcium in bone health The Nutrition Society. 62[4]:851-858.

[4] Goulding A., Cannan R., Williams SM, Gold EJ, Taylor RW, Lewis-Barned N. J.(1998) Bone mineral density in girls with forearm fractures. J Bone Miner Res. 13:143-148.

[5] Goulding A., Jones I. E., Taylor R. W., Williams S. M., Manning P. J. (2001) Bone mineral density and body composition in boys with distal forearm fractures: a dualenergy x-ray absorptiometry study. J Pediatr.139:509-512.

[6] Greer F. R. MD, Nancy F. Krebs, MD, and the Committee on Nutrition (2006) Optimizing Bone Health and Calcium Intakes of Infants, Children, and Adolescents. American Academy of Pediatrics. 2:117-119.

[7] DNPCNCD, 2008. Diet, nutrition and prevention of chronic non-communicable diseases among adolescents. Final report of National Survey of National Nutrition Institute, Egypt.
[8] Ebtissam M. S. Manal A. M., Mai M. Y., Hala S. M., Samar M. E. S. (2012) Effect Of Diet Quality On Bone Mineralization In Obese Egyptian Children And Adolescents. Journal of Applied Sciences Research. 8 [5]:2812-2820.

[9] Harinarayan C. V., Tirupati R., Upadrasta V. P., Desineni S., Pemmaraju VLN. S., and Kumar E. G. T. (2007) High prevalence of low dietary calcium, high phytate consumption, and vitamin D deficiency in healthy south Indians. Am J Clin Nutr. 85[7]:1062-1067.

[10] Hassan, H., A. Abdel Galil, W. Moussa, (2004) National survey for the determination of bone mass density among adolescents and adults in Egypt. Final report. Cairo, National Nutrition Institute.

[11] Ibrahim S. A. M. A. Samy M. A., Matter M. K. and Saleh A. O. L. (2011) Bone mineral density in Egyptian adolescents and adults with short stature: results of a national survey. Eastern Mediterranean Health Journal. 17 [8]:687-693.

[12] ICMR (1992) Nutrient requirements and recommended dietary allowances for Indians. Indian Council Of Medical Research, New Delhi.

[13] James, W. P. T., Ferro-Liuzzi and Waterlow, J. C (1988) Definition of chronic energy deficiency in adults- report of working party of the intervention dietary energy consultation group. Am. J. Clin. Nutr. 42:969-981.

[14] Jelliffe, O. B. (1996) The Assessment Of Nutritional Status Of The Community Monograph Series no.53. World Health Organization, Geneva.

[15] Lerner B. R. Lei D. L., Chaves S. P., Freire R. D. (2000) Consumption of calcium by adolescent from public schools EM OSASCO, SÃO PAULO, BRAZIL. Rev Nutr. -13:57-63.

[16] Rajeshwari R Nicklas TA, Yang SJ, Berenson GS. (2004) Longitudinal changes in intake and food sources of calcium from childhood to young adulthood: the bogalusa heart study. J Am Coll Nut. 23:241-50.

[17] Salamoun M. M., Kizirian A. S., Tannous R. I., Nabulsi M. M., Choucair M. K., Deeb M. E. (2005) Low calcium and vitamin $\mathrm{D}$ intake in healthy children and adolescents and their correlates. Eur J Clin Nutr. 59:177-84.

[18] Soyka L. A. Grinspoon S., Levitsky L. L. (1999) The Effects of Anorexia Nervosa on Bone Metabolism in Female Adolescents. The Journal of Clinical Endocrinology \& Metabolism. 84 [12]:4489-4496. 